\title{
Multispecies Multistrain Probiotic Effects on Calves Development and Health
}

\author{
Mirentxu Indart ${ }^{*}$, Silvia Cerone ${ }^{1}$, Eduardo Néstor Esteban ${ }^{2}$, Guadalupe de Yaniz ${ }^{1}$, \\ Ana Graciela Inza ${ }^{1}$, Herminia Landi ${ }^{3}$, Silvina Mogni ${ }^{1}$, Leticia Igarza ${ }^{1}$ \\ ${ }^{1}$ Department of Physiology and Pathology, Faculty of Veterinary Medicine, Universidad Nacional del Centro de la Provincia de \\ Buenos Aires, Buenos Aires, Argentine \\ ${ }^{2}$ Department of Animal Health, Faculty of Veterinary Science, Universidad Nacional del Centro de la Provincia de Buenos Aires, \\ Buenos Aires, Argentine \\ ${ }^{3}$ Department of Animal Production, Faculty of Veterinary Science, Universidad Nacional del Centro de la Provincia de Buenos Aires, \\ Buenos Aires, Argentine \\ Email: *mindart@vet.unicen.edu.ar
}

Received September 10, 2012; revised October 16, 2012; accepted October 26, 2012

\begin{abstract}
Experiment was designed to assess alimentary security or any beneficial effect on calve of a multispecies multistrain probiotic (MMP). An experiment with 36 calves, two day old, was conducted to assess the influence of probiotic on growth and health indicators. The treatment period was extended to $45 \mathrm{~d}$. Group 1 received one daily dose of MMP (1.1 $\times 10^{9} \mathrm{CFU}$ per calf) during $20 \mathrm{~d}$. Group 2 was the untreated control. On a weekly basis, every calf in each group was weighed to determine weight gain. Forty five days after the beginning of the experiment, blood samples were obtained from seven animals from Group 1 and six from Group 2, and peripheral blood neutrophils separated in order to determine metabolic and microbicidal activity. There was a significant increase in $\mathrm{H}_{2} \mathrm{O}_{2}$ production and NBT reduction test in MMP treated calves. The MMP not only lacks adverse effects when supplied as food additive, but showed health benefits. The prevention of infection and the highly significant increase of phagocytic activity in peripheral blood leukocytes seen in calves strongly suggest an efficient connection between the MMP and the immune system.
\end{abstract}

Keywords: Probiotic; Growth; Health; Immunology; Calves

\section{Introduction}

Raising calves in dairy farms represents a fragile stage for the primary milk production industry in Argentina [1]. The usual stress period after birth is worsened when new born calves are separated from their mothers. Most of these calves are hypogammaglobulinemic due to failure of passive transfer of maternal gammaglobulines, having mild to severe immunological impairment [2]. Factors that often are cited as having an effect on passive transfer in the calf are the timing of colostrum ingestion the method and volume of colostrum administration, the immunoglobulin concentration of the colostrum ingested, and the age of the dam. [3] Passive immunity acquired via transfer of maternal immunoglobulins in colostrum provides newborn mammals with early protection against pathogens. This is particularly important in cattle because calves are born hypogammaglobulinemic and depend solely on transfer from colostrum for antibodymediated immunoprotection [4,5]. Limited or complete failure of transfer of immunoglobulin can result in an

${ }^{*}$ Corresponding author. increased incidence of morbidity, which can contribute to a failure to thrive as evidenced by suboptimal or diminished growth $[6,7]$.

Normal intestinal microbiota seeding is also affected. Consequently, they suffer frequent intestinal and respiratory diseases with increasing morbidity and mortality, affecting weight gain and normal development [8].

Thus, the stressful conditions experienced by animals subjected to high production systems and environment hostilities negatively influence the composition and symbiotic interactions of gut microbiota [9]. The natural nutritional resources are changing, the composition of gut microflora must also change and incorporate higher biodiversity for adaptation to environmental perturbation $[10,11]$. Synthetic pharmaceutical formulations like antibiotics are extensively used as therapeutic or as preventive agents for intestinal diseases in dairy calves. These formulations induce the selection and proliferation of resistant bacterial strains; they are aggressive against host friendly flora deepening the fragility of gut homeostasis [12].

Probiotic represent a promising alternative as a disease 
biocontrol strategy in raising dairy farm calves $[13,14]$. A probiotic is a "live microbial feed supplement which beneficially affects the host animal by improving its intestinal microbial balance" [15]. Thus, using a probiotic means an intervention on the intestinal ecosystem. Probiotic bacteria would have antagonistic impact against intestinal infectious bacteria just by competitive exclusion [16], modulating the intestinal medium, favoring growth of friendly bacteria or producing natural antibiotics or bacteriocines [17].

Perhaps the most intriguing phenomena associated with the consumption of probiotic focuses on their crosstalk capacity with host gut microbiota, observed as early as 1965 [18], host gut cells and host immune system cells $[19,20]$ resulting in immune modulation. This would mean that the identification of probiotic soluble factors would explain the effect beyond intestine, general health improvement and higher resistance against systemic infectious invaders like bacteria, viruses, fungi observed in experimental animals [21]. Many studies, have shown that probiotics increase barrier function in terms of increased mucus, antimicrobial peptides, and sIgA production, competitive adherence for pathogens, and increased tight junctions integrity of epithelial cells [22].

The aim of this work was assess alimentary security and any beneficial effect on calves of a multispecies multistrain probiotic

\section{Materials and Method}

The experiment was carried out in a commercial dairy farm which had a nursery field for its own calves. Calves were exposed to weather conditions without any protection and with no chance to move freely. The regular feed and general management in the nursery were also applied to the selected experimental animals. The animals were followed for 65 day of age. Thirty-six Holstein calves (two days old) were selected for this experiment and separated in two groups of 18 animals per group. The calves were fed twice at day with milk plus colostrum (four $\mathrm{L} / \mathrm{d}$ per calf). Group 1 received one daily dose of probiotic (MMP) per calf during $20 \mathrm{~d}$. One MMP dose was $330 \mathrm{mg}$ biomass containing $1.1 \times 10^{9} \mathrm{CFU}$. Group 2 was the untreated control. The MMP is composed by at least seven lactic acid bacteria and two yeast species, comprising agents from separated dominium like Eukaria and Bacteria (L. helveticus, L. fermentum L. paracasei, $L$. casei, L. parabuchneri, Lactobacillus gasseri and Lactobacillus panis and Pichia Kudravzevii and Sacchoromyces cerevisiae) [23].

All calves in Group 1 and Group 2 were observed daily and any physical and/or clinical change registered. On a weekly basis, every calf in each group was weighed to determine weight gain. Forty five days after the beginning of the experiment, blood samples were obtained from seven animals from Group 1 and six from Group 2 and peripheral blood neutrophils separated [24] in order to determine metabolic and microbicidal activity as follows: Nitroblue tetrazolium (NBT) reduction test: The NBT is a yellow dye that, when incorporated into the phagolysosome, is biochemically transformed in a blue formazan crystal. The more metabolically active cells are the more NBT is incorporated. Two hundred $\mu \mathrm{L}$ NBT solution $(0.11 \%$ in HBSS $), 200 \mu \mathrm{L}$ of neutrophils $(4 \times$ $10^{5}$ ) were mixed with $40 \mu \mathrm{L}$ opsonized zymosan (OpZ) or $100 \mu \mathrm{L}$ of $10 \mu \mathrm{g} / \mathrm{mL}$ phorbol 12 -myristate 13 -acetate (PMA). Duplicate tubes were prepared without stimulant. All tubes were incubated at $37^{\circ} \mathrm{C}$ for $15 \mathrm{~min}$, the reaction was stopped by addition of $3 \mathrm{ml}$ of $0.5 \mathrm{~N} \mathrm{HCl}$. Tubes were centrifuged at $1000 \times \mathrm{g}$ for $10 \mathrm{~min}$, and cells were washed twice with $3 \mathrm{~mL}$ of $0.5 \mathrm{~N} \mathrm{HCl}$ for $5 \mathrm{~min}$. The sediment was re-suspended in $3 \mathrm{ml}$ of dimethylformamide (DMF) and heated in a boiling water bath for $10 \mathrm{~min}$, then $2 \mathrm{ml}$ of $10 \mathrm{~N} \mathrm{KOH}$ was added and mixed thoroughly, centrifuged and the upper DMF layer was read in $\mathrm{OD}_{710}$. The results are expressed as $\Delta \mathrm{OD} / 2 \times 10^{6}$ neutrophils $/ 15$ min [25]. All samples were analyzed in triplicate.

Production of hydrogen peroxide $\left(\mathrm{H}_{2} \mathrm{O}_{2}\right)$ : The test was carried out three times in each isolated cell sample. The production of $\mathrm{H}_{2} \mathrm{O}_{2}$ was determined by the method described by [26] with slight modifications. Two hundred $\mu \mathrm{L}$ of neutrophils suspension $\left(4 \times 10^{5}\right.$ cells $)$, were mixed with $40 \mu \mathrm{L} \mathrm{OpZ}(125 \mu \mathrm{g} / \mathrm{mL})$ or $100 \mu \mathrm{L}$ of $10 \mu \mathrm{g} / \mathrm{mL}$ PMA. Negative controls were prepared without stimulant. All tubes were incubated under an atmosphere of $5 \% \mathrm{CO}_{2} 95 \%$ air at $37^{\circ} \mathrm{C}$. After $1 \mathrm{~h}$ of incubation, a solution of phenol red and $0.2 \mu \mathrm{M}$ horseradish-peroxidase was added to the medium to quantify the hydrogen peroxide content. After $10 \mathrm{~min}$, the reaction was stopped with $100 \mu \mathrm{L}$ of $1 \mathrm{~N} \mathrm{NaOH}$ and the amount of hydrogen peroxide formed was measured spectrophotometrically at $620 \mathrm{~nm}$. Results were expressed as nmol $\mathrm{H}_{2} \mathrm{O}_{2} / 10^{6}$ cells.

\section{Statistical Analyses}

Dates were analyze using GLM procedure of SAS. The initial body weight was used as a covariate for analysis. Mortality, the occurrence of diarrhea, distress respiratory and the animals needing therapeutic treatment were evaluated by means of a $\chi^{2}$ test. The student $t$ test was used to compare the values of NBT reduction test and $\mathrm{H}_{2} \mathrm{O}_{2}$ production in MMP-treated and untreated calves. A value of $\mathrm{p}<0.05$ was considered significant [27].

This study was approved by the Animal Care Committee of the Facultad de Ciencias Veterinarias of Universidad Nacional del Centro de la Provincia de Buenos Aires, Argentina. 


\section{Result}

No negative side effects, like death, depression, emaciation or nervous signs were registered in the treated calves during the experiment. The weight gain showed a tendency to be higher compared to the untreated group: $76.07 \mathrm{~kg}$ (SD: 6.37) vs $70.33 \mathrm{~kg}$ (SD: 9.18). The number of dead calves (0-1) calves with scour $(8-13, \mathrm{p}=0.09)$, calves with respiratory distress $(0-3)$ and calves with antibiotic treatments $(3-5)$ were for treated and control groups, respectively. Subjectively, the hair of the treated calves was brighter and their state of alert was higher.

The Table 1 shows the results obtained by testing the metabolic and microbicidal activity of neutrophils in calves from both groups.

\section{Discussion and Conclusions}

In no case the inclusion of the MMP produced some problems to the health for the calves also if showed health benefits in calves. Brightness of the hair, the state of alert and a tendency to an increased weight gain observed in MMP-treated calves may indicate an improvement at intestine level allowing a better absorption of nutrients induced by probiotic. The MMP treatment shown a tendency in favor of the lower number of calves whit diarrhea $(p>0.09)$. This outcome agrees with that of other studies in calves $[28,29,14]$. The MMP reduced the number of calves whit distress respiratory and the calves whit therapeutic treatments against diarrhea and respiratory disorders, although had not difference significant. Apart from their positive effects on gastrointestinal infections, probiotic may be used to prevent non intestinal infectious conditions, such as respiratory tract infections [30,31]. The present results indicate that this MMP may reduce the mortality and antibiotic treatment in veterinary practice as was observed by Timmerman et al. (2005) [14]. The most impressive observation made in treated calves was the significant increase in metabolic and microbicidal activity in neutrophils. The observation that digestive and respiratory infections diminished in this MMP group when

Table 1. Functionality and microbicidal activity of neutronphils in calves treated with the probiotic and in control calves.

\begin{tabular}{cccc}
\hline Treatment & NBT & $\mathrm{H}_{2} \mathrm{O}_{2}(\mathrm{OpZ})$ & $\mathrm{H}_{2} \mathrm{O}_{2}(\mathrm{PMA})$ \\
\hline Control $(\mathrm{n}=6)$ & $5.5 \pm 3.51$ & $12.4 \pm 7.59$ & $4.3 \pm 1.73$ \\
Probiotic $(\mathrm{n}=7)$ & $27.3 \pm 2.12$ & $35.3 \pm 11.83$ & $23.4 \pm 8.63$ \\
$\mathrm{p}$ & 0.01 & 0.05 & 0.001 \\
\hline
\end{tabular}

n: number of calves, NBT: nitro blue tetrazolium, $\triangle \mathrm{DO} / 1 \times 10^{6} \mathrm{PMN}$; PMA: phorbol myristate acetate; OpZ: opsonized Zymosan, $\mathrm{H}_{2} \mathrm{O}_{2}$ : nmoles $/ 1 \times 10^{6}$ PMN. compared to the untreated group may indicate a good connection between the MMP and the immune system. This situation has been demonstrated in other animal species [32-34].

Host specificity is regarded as a desirable property for probiotic bacteria and therefore recommended as one of the selection criteria $[35,36]$. This criterion was not considered by us during this probiotic development [23]. Biological diversity and symbiosis strengthen adaptability and these three concepts constitute the most impressive characteristics of this probiotic, suggesting that these are significant factors for the success in favoring gut health in calves. Acting as a unit enabling multifunctional coordinated actions, a biodiversities, symbiotic and adaptive community would have better chances to survive, colonize or have a longer residence in gut than a monostrain probiotic. Concerning crosstalk, advantages of the new probiotic would be obvious. As a consequence, up to this date, we only can speculate about the probiotic mechanism of action to achieve the documented beneficial effects in intestine.

The decrease of incidence of respiratory diseases and diarrhea and the highly significant increase of phagocyte activity in peripheral blood leukocytes seen in calves strongly suggest an efficient connection between the probiotic and the immune system. Studies examining gut colonization and dialogue between community members and host are under way.

\section{Acknowledgements}

This work was financially supported by grants PICT062106 from FONCYT (Argentina), from CIC (Buenos Aires-Argentina) and from Secretaría de Ciencia, Arte y Tecnología de la Universidad Nacional del Centro de la Provincia de Buenos Aires.

\section{REFERENCES}

[1] E. R. Marcos and F. Beltramino, "Variaciones Sanguíneas en Terneros de Tambo, Bajo Distintos Tipos de Crianza Artificial," Revista Argentina de Producción Animal, Vol. 4, No. 2, 1984, pp. 225-232.

[2] K. Turgut, A. Basoglu, M. Sevinc, I. Sen and M. Yildiz, "Plasma Transfusion in Calves with Failure of Passive Colostral Transfer," Turkish Journal of Veterinary and Animal Sciences, Vol. 22, No. 2, 1998, pp. 123-130.

[3] D. M. Weaver, J. W. Tyler, D. C. VanMetre, D. E. Hostetler and G. M. Barrington, "Passive Transfer of Colostral Immunoglobulins in Calves," Journal of Veterinary Internal Medicine, Vol. 14, No. 6, 2000, pp. 569577. doi:10.1111/j.1939-1676.2000.tb02278.x

[4] H. Salmon, "The Mammary Gland and Neonate Mucosal Immunity," Veterinary Immunology and Immunopathol$o g y$, Vol. 72, No. 1-2, 1999, pp. 143-155.

doi:10.1016/S0165-2427(99)00127-0 
[5] P. Van de Perre, "Transfer of Antibody via Mother's Milk," Vaccine, Vol. 21, No. 24, 2003, pp. 3374-3376. doi:10.1016/S0264-410X(03)00336-0

[6] G. A. Donovan, G. A. Dohoo, I. R. Montgomery, D. M. and F. L. Bennett, "Associations between Passive Immunity and Morbidity and Mortality in Dairy Heifers in Florida, USA," Preventive Veterinary Medicine, Vol. 34, No. 1, 1998, pp. 31-46. doi:10.1016/S0167-5877(97)00060-3

[7] V. Parreño, C. Béjar, A. Vagnozzi, M. Barranderguy, V. Costantini, M. I. Craig, L. Yuan, D. Hodgins, L. Saif and F. Fernández, "Modulation by Colostrums-Acquired Maternal Antibodies of Systemic and Mucosal Antibody Responses to Rotaviris in Calves Experimentally Challenged with Bovine Rotavirus," Veterinary Immunology and Immunopathology, Vol. 100, No. 1-2, 2004, pp. 7-24.

[8] H. J. Postema, P. Franken and J. B. van der Ven, "A Study in Veal Calves for a Possible Correlation between Serum Immunoglobulin Levels, Nutrition Levels and Risk of Disease in the First Few Weeks of the Fattening Period," Tigdschr Diergeneeskd, Vol. 112, No. 11, 1987, pp. 665-671.

[9] H. Kitano and K. Oda, "Robustness Trade-Offs and Host-Microbial Symbiosis in the Immune System," Molecular Systems Biology, Vol. 2, 2006, Article ID: 2006. 0022. doi:10.1038/msb4100039

[10] L. P. Soto, L. S. Frizzo, E. Bertozzi, E. Avatanco, G. J. Sequeira and M. R. Rosmini, "Molecular Microbial Analysis of Lactobacillus Strains Isolated from the Gut of Calves for Potential Probiotic Use," Veterinary Medicine International, Vol. 2010, 2010, Article ID: 274987. doi: $10.4061 / 2010 / 274987$

[11] V. Mai and P. V. Draganov, "Recent Advances and Remaining Gaps in Our Knowledge of Associations between gut Microbiota and Human Health," World Journal of Gastroenterology, Vol. 15, No. 1, 2009, pp. 81-85. doi:10.3748/wig. 15.81

[12] P. D. Constable, "Antimicrobial Use in the Treatment of Calf Diarrhea," Journal of Veterinary Internal Medicine, Vol. 18, No. 1, 2004, pp. 8-17. doi:10.1111/j.1939-1676.2004.tb00129.x

[13] H. M. Timmerman, C. J. Koning, L. Mulder, F. M. Rombouts and A. C. Beynen, "Monostrain, Multistrain and Multispecies Probiotics. A Comparison of Functionality and Efficacy," International Journal of Food Microbiology, Vol. 96, No. 3, 2004, pp. 219-233. doi:10.1016/j.ijfoodmicro.2004.05.012

[14] H. M. Timmerman, L. Mulder, H. Everts, D. C. van Espen, E. van der Wal, G. Klaassen, S. M. Rouwers, R. Hartemink, F. M. Rombouts and A. C. Beynen, "Health and Growth of Veal Calves Fed Milk Replacers with or without Probiotics," Journal of Dairy Science, Vol. 88, No. 6, 2005, pp. 2154-2165. doi:10.3168/jds.S0022-0302(05)72891-5

[15] R. Fuller, "Probiotics in Man and Animals," Journal of Applied Bacteriology, Vol. 66, No. 5, 1989, pp. 365-378. doi:10.1111/j.1365-2672.1989.tb05105.x

[16] X. Chen, J. Xu, J. Shuai, J. Chen, Z. Zhang and W. Fang, "The S-Layer Proteins of Lactobacillus crispatus Strain
ZJ001 Is Responsible for Competitive Exclusion against Escherichia coli O157:H7 and Salmonella typhimurium," International Journal of Food Microbiology, Vol. 115, No. 4 , 2007, pp. 307-312.

doi:10.1016/j.ijfoodmicro.2006.11.007

[17] R. D. Rolfe, "The Role of Probiotic Cultures in the Control of Gastrointestinal Health," Journal of Nutrition, Vol. 130, No. 2, 2000, pp. 3965-4025.

[18] D. M. Lilly and R. H. Stillwell, "Probiotics: GrowthPromoting Factors Produced by Microorganisms," Science, Vol. 147, No. 3659, 1965, pp. 747-748. doi:10.1126/science.147.3659.747

[19] W. M. de Vos, P. A. Bron and M. Kleerebezem, "PostGenomics of Lactic Acid Bacteria and Other Food-Grade Bacteria to Discover Gut Functionality," Current Opinion Biotechnology, Vol. 15, No. 2, 2004, pp. 86-93. doi:10.1016/j.copbio.2004.02.006

[20] R. N. Oozeer, Goupil-Feuillerat, C. A. Alpert, M. van de Guchte, J. Anba, J. Mengaud and G. Corthier, "Lactobacillus casei Is Able to Survive and Initiate Protein Synthesis during Its Transit in the Digestive Tract of Human Flora-Associated Mice," Applied and Environmental Microbiology, Vol. 68, No. 7, 2002, pp. 3570-3574. doi:10.1128/AEM.68.7.3570-3574.2002

[21] M. F. Montalto, F. Arancio, D. Izzi, L. Cuoco, V. Curigliano, R. Manna and G. G. Gasbarrini, "Probiotics: History, Definition, Requirements and Possible TheraPeutic Applications," Annali Italiani di Medicina Interna, Vol. 17, No. 3, 2002, pp. 157-165.

[22] C. L. Ohland and W. K. MacNaughton, "Probiotic Bacteria and Intestinal Epithelial Barrier Function," American Journal of Physiology, Gastrointestinal and Liver Physiology, Vol. 298, No. 6, 2010, pp. G807-G819. doi:10.1152/ajpgi.00243.2009

[23] E. N. Esteban, M. Indart, S. Cerone, G. de Yaniz, A. G. Inza, H. Landi, S. Mogni, M. Juliarena and L. Igarza, "Production and Biochemestry-Molecular Analysis of Microbial Community Fermenting Whey as a Potential Probiotic for Use Animals," Open Journal of Veterinary Medicine, Vol. 2, No. 3, 2012, (in Press). doi:10.4236/ojvm

[24] O. Barta, L. Shaffer and L. J. Huang, "Separation of Lymphocytes, Monocytes and Neutrophils," In O. Barta Ed., Laboratory Techniques of Veterinary Immunology, Thomas, Springfield, 1984, pp. 31-42.

[25] H. Nagahata, A. Yatsu and H. Noda, "The Evaluation of a Quantitative Assay for Estimating the Bactericidal Activity of Bovine Neutrophils by Nitroblue Tetrazolium Reduction," British Veterinary of Journal, Vol. 142, No. 6, 1986, pp. 578-584. doi:10.1016/0007-1935(86)90117-X

[26] E. Pick and D. Mizel, "Rapid Microassays for the Measurement of Superoxide and Hydrogen Production by Macrophages in Culture Using an Automatic Enzyme Immunoassay Reader," Journal of Immunology Methods, Vol. 46, No. 2, 1981, pp. 211-226. doi:10.1016/0022-1759(81)90138-1

[27] SAS Institute, "User's Guide," Statistics, SAS Institute, Inc., Cary, 2002. 
[28] F. Abe, N. Ishibashi and S. Shimamura. "Effect of Administration of Bifidobacteria and Lactic Acid Bacteria to Newborn Calves and Piglets," Journal of Dairy Science, Vol. 78, No. 12, 1995, pp. 2838-2846. doi:10.3168/jds.S0022-0302(95)76914-4

[29] D. C. Donovan, S. T. Franklin and C. C. L. Chase, "Growth and Health of Holstein Calves Fed Milk Replacers Supplemented with Antibiotics or Enteroguard," Journal of Dairy Science, Vol. 85, No. 4, 2002, pp. 947950. doi:10.3168/jds.S0022-0302(02)74153-2

[30] S. Racedo, J. Villena, M. Medina, G. Agüero, V. Rodriguez and S. Alvarez, "Lactobacilus casei Administration Reduces Lung Injuries in a Streptococcus pneumonia Infection in Mice," Microbes and Infection, Vol. 8, No. 9-10, 2006, pp. 2359-2366. doi:10.1016/j.micinf.2006.04.022

[31] H. H. Musa, S. L. Wu, C. H. Zhu, H. I. Seri and G. Q. Zhu, "The Potential Benefits of Probiotics in Animal Production and Health," Journal of Animal and Veterinary Advances, Vol. 8, No. 2, 2009, pp. 313-321.

[32] H. R. Haghighi, M. F. Abdul-Careem, R. A. Dara, J. R. Chambers and S. Sharif, "Cytokine Gene Expression in Chicken Cecal Tonsils Following Treatment with Probi- otics and Salmonella Infection," Veterinary Microbiology, Vol. 126, No. 1-3, 2008, pp. 225-233.

doi:10.1016/j.vetmic.2007.06.026

[33] G. Vinderola, C. Matar and G. Perdigón, "Role of Intestinal Epithelial Cells in Immune Effects Mediated by Gram-positivo Probiotic Bacteria: Involvement of TollLike Receptors," Clinical Diagnostic Laboratory Immunology, Vol. 12, No. 9, 2005, pp. 1075-1084.

[34] C. M. Galdeano and G. Perdigón, "Role of Viability of Probiotic Strains in Their Persistence in the Gut and in Mucosal Immune Stimulation," Journal of Applied Microbiology, Vol. 97, No. 4, 2004, pp. 673-681. doi:10.1111/j.1365-2672.2004.02353.x

[35] S. Salminen, M. A. Deighton, Y. Benno and S. L. Gorbach, "Lactic Acid Bacteria in Health and Disease," In: S. Salminen and A. von Wright, Eds., Lactic Acid Bacteria. Microbiology and Functional Aspects, 2nd Edition, Marcel Dekker, New York, 1998, pp. 211-253.

[36] M. Saarela, G. Mogensen, R. Fonden, J. Matto and T. Mattila-Sandholm, "Probiotic Bactria: Safety, Functional and Technological Properties," Journal of Biotechnology, Vol. 84, No. 3, 2000, pp. 197-215. 